\title{
Conduction disorders after aortic valve replacement: what is the real impact of sutureless and rapid deployment valves?
}

\author{
Paolo Berretta ${ }^{1}$, Luca Montecchiani ${ }^{1}$, Fabio Vagnarelli ${ }^{2}$, Mariano Cefarelli ${ }^{1}$, Jacopo Alfonsi ${ }^{1}$, \\ Carlo Zingaro $^{1}$, Filippo Capestro ${ }^{1}$, Michele D. Pierri ${ }^{1}$, Alessandro D'alfonso ${ }^{1}$, Marco Di Eusanio ${ }^{1}$ \\ ${ }^{1}$ Cardiac Surgery Unit, Lancisi Cardiovascular Center, Polytechnic University of Marche, Ancona, Italy; ${ }^{2}$ Cardiology Unit, Lancisi Cardiovascular \\ Center, Ancona, Italy \\ Correspondence to: Paolo Berretta, MD. Cardiac Surgery Unit, Lancisi Cardiovascular Center, Polytechnic University of Marche, Via Conca 71, \\ 60126, Ancona, Italy. Email: p.berretta@icloud.com.
}

Background: Although sutureless and rapid deployment aortic valve replacement (SURD-AVR) has been associated with an increased rate of permanent pacemaker (PPM) implantation compared to conventional AVR (c-AVR), the predictors of new conduction abnormalities remain to be clarified. This study aimed to identify risk factors for conduction disorders in patients undergoing AVR surgery.

Methods: Data from 243 patients receiving minimally invasive AVR were prospectively collected. SURDAVR was performed in 103 (42.4\%) patients and c-AVR in 140 (57.6\%). The primary endpoint was the occurrence of new-onset conduction disorders, defined as first degree atrioventricular (AV) block, advanced AV block requiring PPM implantation, left anterior fascicular block (LAFB), left bundle branch block (LBBB) and right bundle branch block (RBBB).

Results: The unadjusted comparison revealed that SURD-AVR was associated with a higher rate of advanced AV block requiring PPM when compared with c-AVR (10.5\% vs. 2.1\%, P=0.01). After adjusting for other measured covariates (OR: 1.6, $\mathrm{P}=0.58)$ and for the estimated propensity of SURD-AVR (OR: 5.1, $\mathrm{P}=0.1$ ), no significant relationship between type of AVR and PPM implantation emerged. On multivariable analysis, preoperative first-degree AV block (OR: 6.9, P=0.04) and RBBB (OR: 6.9, P=0.03) were independent risk factors for PPM. Subgroup analysis of patients with normal preoperative conduction revealed similar incidence of PPM between SURD-AVR and c-AVR (1.3\% vs. 1.9\%, $\mathrm{P}=0.6)$. When compared with c-AVR, SURD-AVR was associated with a greater incidence of postoperative new onset LBBB (18.1\% vs. $3.2 \%$, $\mathrm{P}<0.001)$. This finding was confirmed after adjusting for the estimated propensity of SURD-AVR (OR: 6.3, $\mathrm{P}=0.009)$.

Conclusions: Our study revealed that the risk of PPM implantation in patients receiving surgical AVR is heavily influenced by the presence of pre-existing conduction disturbances rather than the type of valve prosthesis. Conversely, SURD-AVR emerged as an independent predictor for LBBB and was associated with an increased risk of PPM in patients presenting with RBBB.

Keywords: Sutureless aortic valve replacement; rapid deployment aortic valve replacement; conduction disorders; aortic valve replacement (AVR)

Submitted Feb 24, 2020. Accepted for publication May 04, 2020.

doi: 10.21037/acs-2020-surd-26

View this article at: http://dx.doi.org/10.21037/acs-2020-surd-26 


\section{Introduction}

The introduction of sutureless and rapid deployment aortic valve replacement (SURD-AVR) (1) has advanced the surgical treatment of aortic valve disease by facilitating the valve implantation process, reducing operative durations and promoting minimally invasive surgery $(2,3)$ SURDAVR has been associated with promising results in patients of all risk categories (4) and demonstrated improved valve hemodynamics when compared with conventional aortic valve replacement (c-AVR) $(5,6)$. Conduction disorders requiring permanent pacemaker (PPM) implantation have emerged as a noteworthy complication associated to SURDAVR interventions (6-9). In recent multicenter series, the prevalence of PPM in patients undergoing SURD-AVR ranges from $7.7 \%$ to $10.4 \%$ compared with $3.3-3.7 \%$ for those undergoing c-AVR $(8,10,11)$. Given their recent development, SURD technologies have been demonstrated to be strongly influenced by the 'learning curve effect', with improving outcomes over time (10). Data from the Sutureless and Rapid Deployment International Registry (SURD-IR) demonstrated a substantial reduction in the rate of PPM over time, from 20.6\% to 5.6\% (2). Currently, only scarce data are available regarding the risk factors of new conduction abnormalities and PPM implantation after surgical AVR and the real impact of SURD valves prostheses remains to be clarified. The aim of this study was to evaluate the incidence, predictors and clinical outcomes of conduction disorders and PPM placement after surgical AVR.

\section{Methods}

\section{Study population and analysis plan}

Between September 2016 and December 2018, data from 243 consecutive patients who underwent minimally invasive aortic valve replacement in our institution were prospectively collected. Of these, 103 (42.4\%) underwent SURD-AVR and 140 (57.6\%) underwent c-AVR. Preoperative, intraoperative and postoperative data were stratified by the type of intervention (SURD-AVR $v s$. c-AVR) and the results were presented using statistical methods controlling for treatment-selection bias (propensity score analysis). Patients were excluded if they had preoperative active endocarditis, a permanent pacemaker, complete heart block on electrocardiogram (ECG), emergency surgery or any concomitant surgical procedure. ECGs were recorded every day in the intensive care unit
(ICU) and in the sub-intensive care unit, the day of transfer to the regular ward and at discharge, unless otherwise stated because of any alteration from the basal rhythm or angina. All patients had continuous telemetry monitoring for at least the first 5 days after the operation or for a longer period if needed. Antiarrhythmic therapy was recorded every day from the admission to the discharge. Occurrence of new conduction abnormalities was assessed from the final ECG, at discharge, or from the ECG before PPM implantation. All ECGs were analyzed by two independent physicians (FV and LM) and the diagnosis of conduction disorders was based on the current recommendations (12).

Following the procedure, the decision to perform PPM implantation was made by an experienced cardiac electrophysiology specialist team in accordance with European Society of Cardiology guidelines on cardiac pacing and cardiac resynchronization therapy (13). The primary endpoints were the occurrence of new-onset conduction disorders within 30 days of the intervention, defined as first-degree atrioventricular (AV) block, advanced AV block requiring PPM implantation, left bundle branch block (LBBB), right bundle branch block (RBBB) and left anterior fascicular block (LAFB). Secondary endpoints were 1-year occurrence of PPM implantation, death from any cause and rehospitalization. The patients were followed by outpatients' clinic and telephone calls. Follow-up was $100 \%$ completed. Patient-informed consent for treatment, data collection and analysis for scientific purposes was collected in all cases and the local Institutional Review Board approved the use of data for research.

\section{Surgical technique}

Our multidisciplinary minimally invasive approach for AVR involving reduced chest incisions, with an expanded use of SURD valves, minimally invasive extracorporeal circulation (MiECC) systems and ultra fast track (UFT) anaesthesia followed by early physiotherapy and family contact in the intensive care unit (ICU), has been previously reported $(14,15)$. In brief, following a $4-5 \mathrm{~cm}$ skin incision, an upper "J" ministernotomy extended to the $3^{\text {rd }}$ or $4^{\text {th }}$ right intercostal space (ICS) or a right anterior thoracotomy (ART) at the 2 nd ICS was performed. The ascending aorta, the axillary or femoral arteries, were cannulated for cardiopulmonary bypass inflow and the right atrium or femoral vein for venous drainage. The right superior pulmonary vein was cannulated for left ventricle venting. The ascending aorta was gently clamped and blood 
cardioplegia was delivered in antegrade fashion via the aortic root or directly into the coronary arteries. Following aortotomy, the aortic cusps were removed and the annulus accurately decalcified. After proper sizing, a sutured or a rapid deployment-Intuity Elite (Edwards Lifesciences, Irvine, CA, USA)—or sutureless-Perceval S (LivaNova, London, UK) — valve was implanted. In patients receiving SURD-AVR annular decalcification was complete as for c-AVR and oversizing carefully avoided. Local anaesthetic infiltration of suture and drains sites was used for immediate postoperative pain relief in UFT-treated patients. Table extubation was performed if extubation criteria were fulfilled (14). After the operation, the patient was transferred to the ICU; mobilization and respiratory therapy as well as oral feeding were started 3-5 hours after surgery. If no complications occurred, the drains were removed and the patient was transferred to the sub-intensive care unit within 12 hours (16).

\section{Statistical analysis}

Continuous variables were expressed as mean \pm standard deviation (SD) and categorical variables as percentages. Where continuous variables did not follow a normal distribution (tested using the Kolmogorov-Smirnov test for normality and Q-Q plots), the median and interquartile range (IQR) were reported. Missing data were not defaulted to negative, and denominators reflect cases reported. The Student t-test and Mann-Whitney $U$ test were used for continuous variables. The Pearson chi-squared or Fisher exact test was used for categoric variables. Univariate analyses were performed to determine relationships between measured variables and occurrence of conduction disorders. AVR type and variables that achieved $\mathrm{p}$ values less than 0.05 in the univariate analyses (Table S1) were examined using multivariable analysis by Firth's logistic regression to estimate the independent effects of risk factors for postoperative conduction disorders.

From a non-parsimonious multivariable logistic regression with AVR technique as the dependent variable and 21 preoperative and intraoperative relevant covariates as the independent variables (age, NYHA class, hypertension, obesity, diabetes, type of aortic valve disease, bicuspid aortic valve, coronary artery disease, acute myocardial infarction, pulmonary hypertension, cerebrovascular disease, peripheral vasculopathy, renal insufficiency, chronic lung disease, reduced left ventricular function, Euroscore II, surgical approach, MiECC, CPB time, cross-clamp time), a propensity score (PS) was derived from the conditional probability that a given patient would undergo SURDAVR. To control for treatment selection biases, the PS for each patient was used as an adjusting variable in the logistic regression model. Time-to-event analyses were performed with the use of Kaplan-Meier estimates and were compared with the use of the log-rank test. $\mathrm{P}$ values $<0.05$ were considered statistically significant. Statistical analysis was performed using Statistical Package for Social Sciences version 25.0 (IBM SPSS Inc., Chicago, IL, USA).

\section{Results}

\section{Patients' characteristics and operative data}

The SURD-AVR patients were older than c-AVR patients (77.7 vs. 71 years; $\mathrm{P}<0.001$ ) with a higher prevalence of female gender $(65 \%$ vs. $41.4 \%, \mathrm{P}<0.001)$. Patients treated with c-AVR were more likely to have bicuspid aortic valve (BAV) $(29.3 \%$ vs. $1 \%, \mathrm{P}<0.001)$, reduced left ventricular function $(35.5 \%$ vs. $21.2 \%, \mathrm{P}=0.02)$, renal failure $(32 \%$ vs. $17.1 \%, \mathrm{P}=0.009)$ and aortic regurgitation $(15 \%$ vs. $1 \%$, $\mathrm{P}<0.001)$. When compared with c-AVR group, SURD-AVR patients more frequently underwent ART (11.7\% vs. 2.9\%, $\mathrm{P}=0.008)$. The baseline characteristics and the operative data of the two groups are listed in Table 1.

Baseline conduction disorders were noted in 52 (24.3\%) patients with no differences between groups (SURDAVR 20\%, c-AVR 27.4\%, P=0.3) (Table 2). The main ECG abnormalities were RBBB ( $\mathrm{n}=18,7.4 \%)$, first-degree AV block (n=16, 6.6\%), LAFB ( $n=16,6.6 \%)$ and LBBB $(\mathrm{n}=12,4.9 \%)$. Prevalence and type of antiarrhythmic drugs were similar between groups (Table 2). Logistic regression identified older age (OR 1.061 at increments of 1 year; CI 1.001-1.131; $\mathrm{P}=0.04$ ), type of valve disease (aortic regurgitation, $\mathrm{OR} 0.07 ; 0.008-0.584 ; \mathrm{P}=0.014)$, aortic valve morphology (BAV, OR 0.291; 0.111-0.753; $\mathrm{P}=0.01$ ) and ART (OR 6.513; 1.07-40.03; $\mathrm{P}=0.04$ ) to be independent predictors for SURD-AVR.

\section{Thirty-day and 1-year outcomes}

Early outcomes were comparable between groups (Table 3). The overall 30-day mortality was $0.8 \%(\mathrm{n}=2)$, with a stroke rate of $1.2 \%(n=3)$. Globally, primary endpoint occurred in $36(16.8 \%)$ patients and a PPM was implanted in 14 $(5.8 \%)$ cases (Table 4). The unadjusted comparison revealed that SURD-AVR was associated with a higher rate of 
Table 1 Patients characteristics and operative data

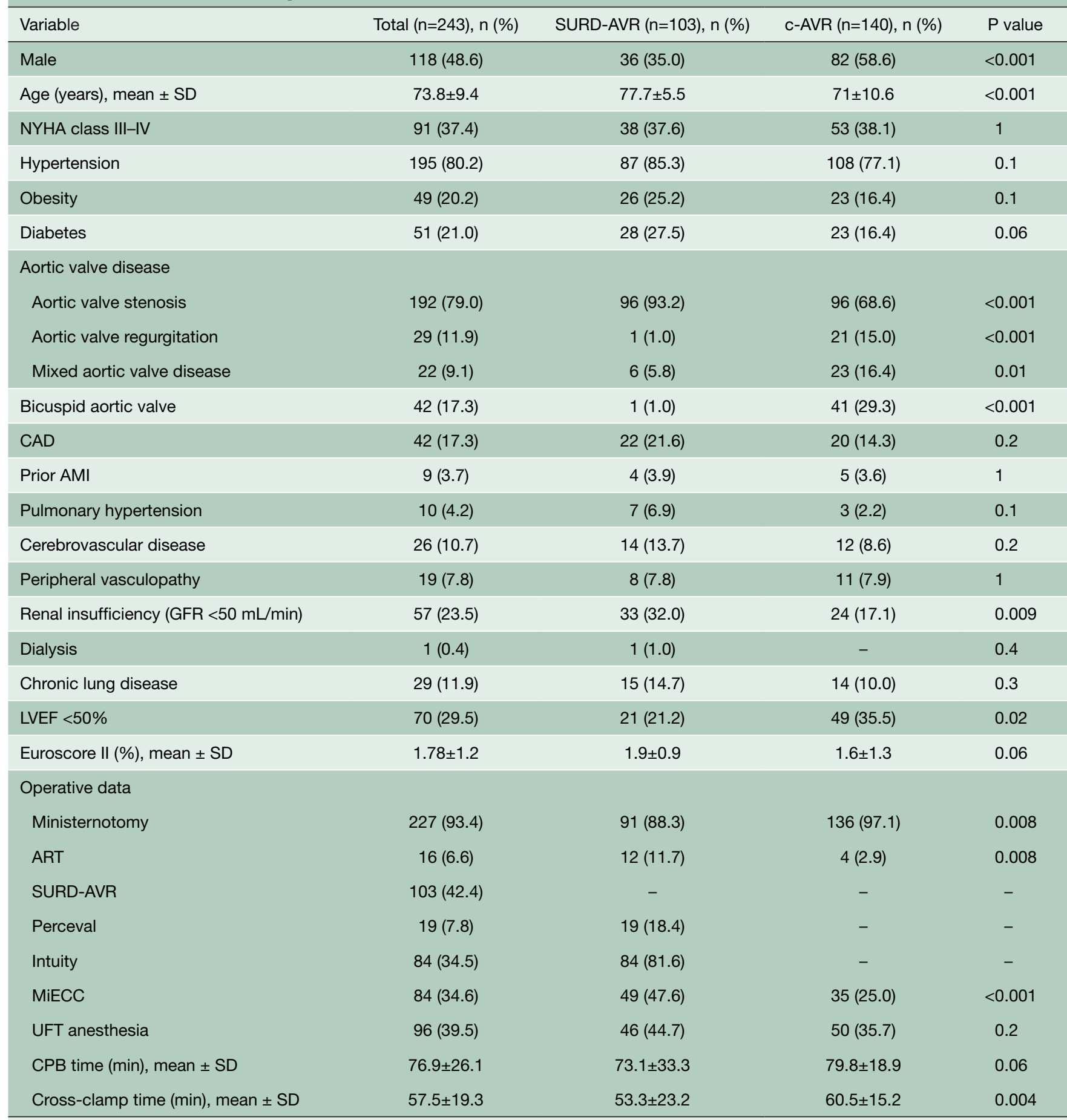

AMI, acute myocardial infarction; ART, anterior right thoracotomy; CAD, coronary artery disease; c-AVR, conventional aortic valve replacement; CPB, cardio-pulmonary bypass; LVEF, left ventricular ejection fraction; MiECC, minimally invasive extracorporeal circulation; GFR, glomerular filtration rate; SD, standard deviation; SURD-AVR, sutureless and rapid deployment aortic valve replacement; UFT, ultra fast track. 
Table 2 Preoperative ECG data and antiarrhythmic therapy

\begin{tabular}{|c|c|c|c|c|}
\hline Variable & Overall (n=243), n (\%) & SURD-AVR (n=103), n (\%) & c-AVR (n=140), n (\%) & $P$ value \\
\hline Atrial fibrillation & $10(4.1)$ & $3(3.3)$ & $7(5.6)$ & 0.5 \\
\hline Conduction disorders & $52(24.3)$ & $18(20.0)$ & $34(27.4)$ & 0.3 \\
\hline First degree AV block & $16(6.6)$ & $8(8.9)$ & $8(6.5)$ & 0.6 \\
\hline LBBB & $12(4.9)$ & $3(3.3)$ & $9(7.3)$ & 0.3 \\
\hline LAFB & $16(6.6)$ & $4(4.4)$ & $12(9.7)$ & 0.2 \\
\hline \multicolumn{5}{|l|}{ Antiarrhythmic drugs } \\
\hline Beta blocker & $99(40.7)$ & $38(42.2)$ & $61(48.8)$ & 0.4 \\
\hline Digoxin & $4(1.6)$ & $1(1.1)$ & $3(2.4)$ & 0.6 \\
\hline
\end{tabular}

$\mathrm{AV}$, atrioventricular; c-AVR, conventional aortic valve replacement; LAFB, left anterior fascicular block; LBBB, left bundle branch block; RBBB, right bundle branch block; SURD-AVR, sutureless rapid deployment aortic valve replacement.

Table 3 30-day outcomes

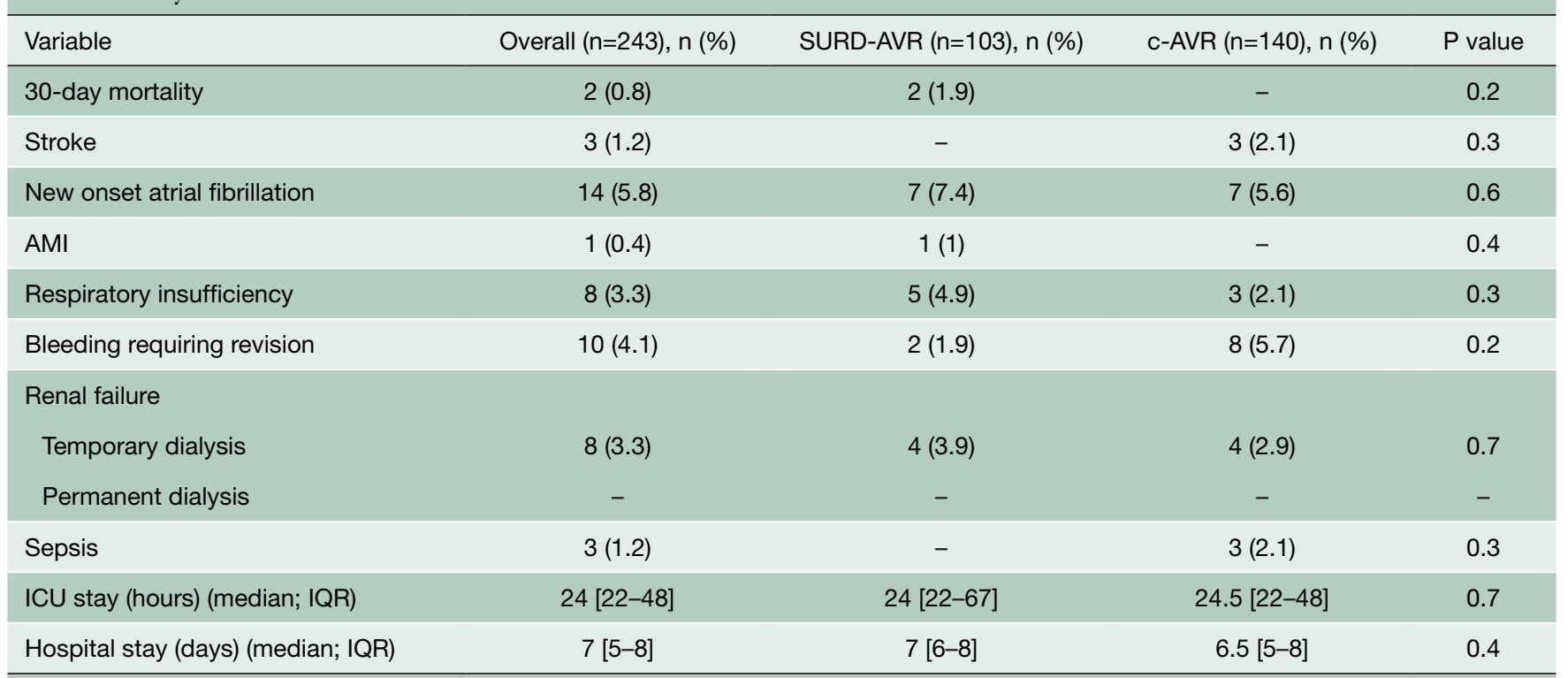

AMI, acute myocardial infarction; c-AVR, conventional aortic valve replacement; ICU, intensive care unit; IQR, interquartile range; SURD-AVR, sutureless and rapid deployment aortic valve replacement. 


\begin{tabular}{|c|c|c|c|c|}
\hline Variable & Overall (n=243), n (\%) & SURD-AVR $(\mathrm{n}=103), \mathrm{n}(\%)$ & C-AVR (n=140), n (\%) & $P$ value \\
\hline New onset conduction disorders & $36(16.8)$ & $27(30.0)$ & $9(7.3)$ & $<0.001$ \\
\hline First degree AV block & $3(1.2)$ & - & $3(2.4)$ & 0.3 \\
\hline PPM implantation & $14(5.8)$ & $11(10.5)$ & $3(2.1)$ & 0.01 \\
\hline Second degree AV block & $1(0.5)$ & $1(1.1)$ & - & 0.4 \\
\hline Third degree AV block & $13(5.4)$ & $10(10.6)$ & $3(2.4)$ & 0.02 \\
\hline Time from operation to implant (days), mean \pm SD & $8.4 \pm 4.6$ & $8.2 \pm 5.1$ & $9 \pm 2.6$ & 0.8 \\
\hline RBBB & $2(0.8)$ & $2(2.1)$ & - & 0.2 \\
\hline LBBB & $21(8.6)$ & $17(18.1)$ & $4(3.2)$ & $<0.001$ \\
\hline LAFB & $1(0.4)$ & $1(1.1)$ & - & 0.4 \\
\hline \multicolumn{5}{|l|}{ Antiarrhythmic therapy } \\
\hline Beta blocker & $111(45.7)$ & $44(50.0)$ & $67(53.6)$ & 0.7 \\
\hline Calcium channel blockers & $3(1.2)$ & $1(1.1)$ & $2(1.6)$ & 1 \\
\hline Amiodarone & $70(28.8)$ & $31(35.2)$ & $39(31.2)$ & 0.5 \\
\hline Digoxin & $5(2.1)$ & $1(1.1)$ & $4(3.2)$ & 0.6 \\
\hline
\end{tabular}

advanced AV block requiring PPM implantation (10.5\% vs. $2.1 \%, \mathrm{P}=0.01)$. Nevertheless, after adjusting for other measured covariates (OR: 1.608, 95\% CI: 0.301-10.741, $\mathrm{P}=0.58)$ and for the estimated propensity of SURD-AVR (OR: 5.102, 95\% CI: 1.001-14.663, $\mathrm{P}=0.1$ ) using logistic regression models, no significant relationship between type of AVR technique and PPM implantation emerged. On multivariable analysis, preoperative first-degree AV block (OR 6.917, 95\% CI: 1.113-13.347, $\mathrm{P}=0.04$ ) and RBBB (OR 6.883, 95\% CI: 1.166-13.640, $\mathrm{P}=0.03$ ) emerged as independent risk factors for PPM implantation (Figure 1A). In patients with normal preoperative conduction, SURDAVR and c-AVR revealed similar incidence of PPM implantation $(1.3 \%$ vs. $1.9 \%, \mathrm{P}=0.6)$. Subgroup analysis of patients receiving SURD-AVR identified $\mathrm{RBBB}$ as the only predictor for PPM implantation (OR 21.094, 95\% CI: 16.247-35.078, $\mathrm{P}=0.001$ ).

When compared with c-AVR, SURD-AVR was associated with a greater incidence of postoperative new onset LBBB (18.1\% vs. 3.2\%, $\mathrm{P}<0.001)$. This finding was confirmed after adjusting for the estimated propensity of SURD-AVR (OR: 6.314, 95\% CI: 1.572-15.061, P=0.009).
On multivariable logistic regression, SURD-AVR (OR 4.807, 95\% CI: $1.714-16.313, \mathrm{P}=0.002)$ and preoperative first-degree AV block (OR 3.773, 95\% CI: 1.029-13.183, $\mathrm{P}=0.04)$ emerged as independent predictors of $\mathrm{LBBB}$ (Figure 1B). Preoperative and postoperative antiarrhythmic drugs showed no relationship with the occurrence of any conduction disorders both in SURD-AVR and c-AVR groups.

At 1 year, the estimated survival was $98.1 \% \pm 1.4 \%$ for SURD-AVR patients and $96.3 \% \pm 1.6 \%$ for c-AVR patients $(\log$ rank $\mathrm{P}=0.29)$ with a rehospitalization rates of $98.6 \% \pm 1.4 \%$ and $96.5 \% \pm 1.7 \%$, respectively (log rank $\mathrm{P}=0.21$ ) (Figure $2 A, B)$. Only 1 patient (c-AVR) required late PPM implantation, 5 months after c-AVR intervention, owing to reoperative AVR for active endocarditis.

\section{Discussion}

The main findings of the present study can be summarized as follows:

(I) Pre-existing RBBB and first-degree AV block were strong independent predictors of PPM 


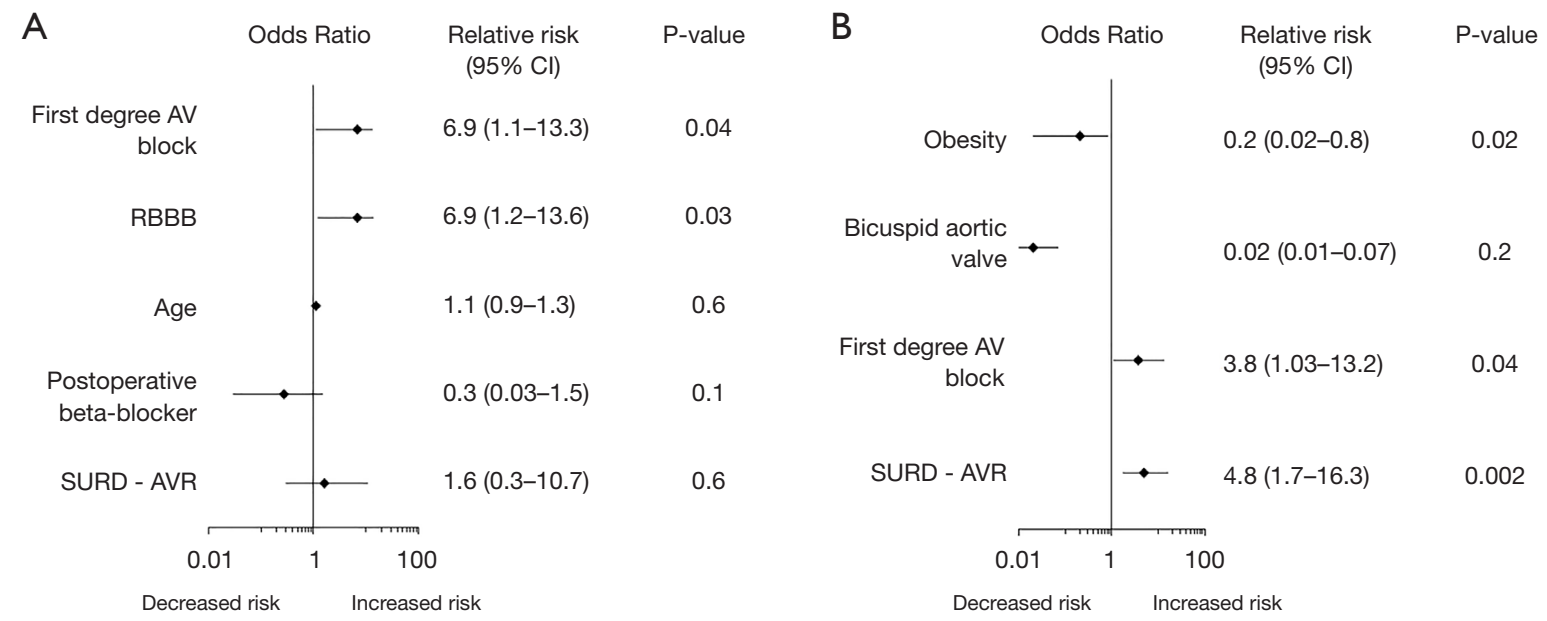

Figure 1 Logistic regression (forest plot) for PPM implantation (A) and new onset LBBB (B). AV, atrioventricular; CI, confidence interval; LBBB, left bundle branch block; RBBB, right bundle branch block; SURD-AVR, sutureless and rapid deployment aortic valve replacement.
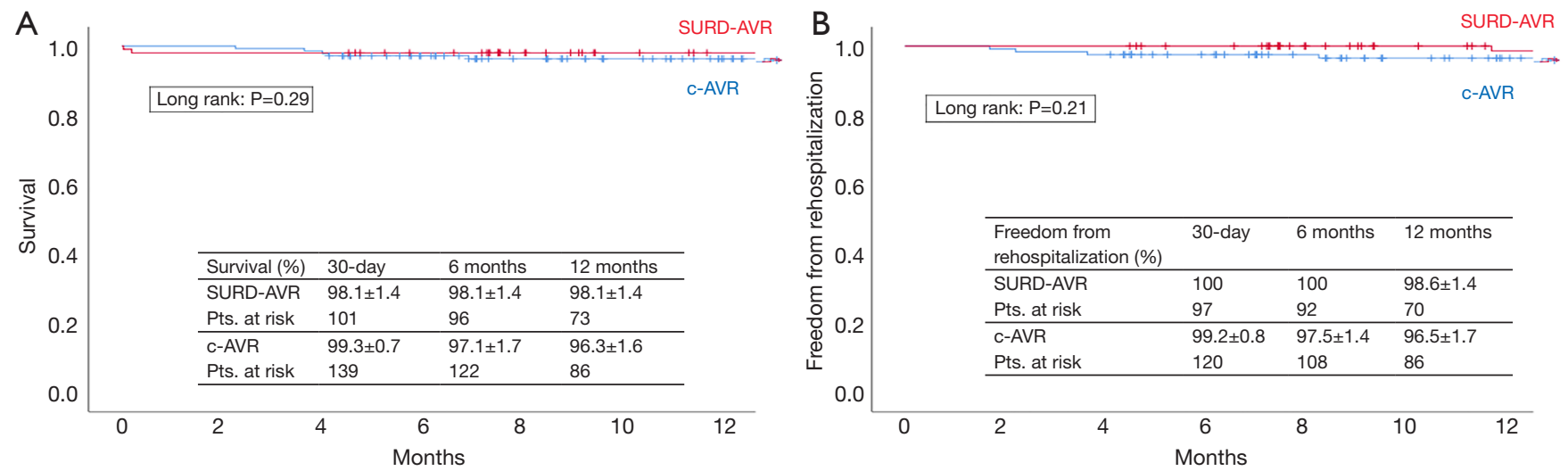

Figure 2 Kaplan-Meier estimates of survival (A) and freedom from rehospitalization from cardiac events (B). c-AVR, conventional aortic valve replacement; SURD-AVR, sutureless and rapid deployment aortic valve replacement.

implantation after surgical AVR.

(II) While SURD-AVR was associated with an increased risk of postoperative conduction abnormalities when compared with c-AVR, in patients with normal preoperative conduction, SURD-AVR and c-AVR revealed similarly low incidences of PPM.

(III) SURD-AVR emerged as a strong risk factor for new onset LBBB and was associated to a markedly increased risk of PPM in patients with pre-existing RBBB.

(IV) Preoperative and postoperative antiarrhythmic therapies appear to have no impact on the occurrence of conduction abnormalities after AVR.

Although the prevalence of PPM implantation in patients undergoing surgical AVR is substantially lower compared to those undergoing TAVR, the risk of conduction abnormalities after surgical AVR remains not negligible (17-20). This is mirrored by a PPM rate and conduction disorders rate in our cohort of $5.8 \%$ and $16.8 \%$, respectively. The occurrence of conduction disturbances after AVR is related to the close anatomical proximity of the atrioventricular conduction system to the aortic valve complex as well as the high prevalence of comorbid conduction system disease in patients with advanced aortic stenosis $(21,22)$. In our study population, $52(24.3 \%)$ 
patients presented with preoperative conduction disorders and these abnormalities strongly-and negativelyinfluenced postoperative results. The presence of preexisting conduction disorders was associated with a considerably higher rate of PPM when compared with patients with normal preoperative AV conduction (11.5\%, vs. $1.9 \%, \mathrm{P}=0.007)$. In particular, on multivariable analysis, pre-existing $\mathrm{RBBB}$ and first-degree $\mathrm{AV}$ block were identified as strong predictors of PPM implantation. It must be noted that SURD-AVR, per se, did not correlate with an increased risk of PPM. We believe this result deserves to be highlighted. Indeed, previous comparative studies between SURD-AVR and c-AVR suggested that SURD-AVR was associated with an increased rate of PPM with no difference between patient risk profiles $(6,8,9,23,24)$.

The real impact of SURD valve technology was likely negatively biased as none of the prior published analyses adjusted for pre-existing conduction abnormalities. Our study demonstrated that SURD-AVR and c-AVR were associated with similarly low incidences of PPM in patients with normal preoperative AV conduction (1.3\% vs. $1.9 \%$, $\mathrm{P}=0.6$ ). Conversely, consistent with data reported by others $(25,26)$, SURD-AVR emerged as risk factor for new onset LBBB. A possible explanation of this finding may be the radial force of the stented frame of SURD valve prostheses imposes pressure on the conduction system embedded in the interventricular septum within few millimeters from the aortic valve and compromises the left bundle branch. The prognostic implications of iatrogenic LBBB remain to be defined; it has been reported that AVR-induced LBBB may be associated with an increased incidence of adverse events defined as the occurrence of advanced AV block requiring PPM, syncope or sudden cardiac death, with most adverse events occurring in the first year after AVR (27). This observation was not confirmed by our analysis. At 1 year, no death, PPM implantation or rehospitalization from cardiac events occurred in patients suffering from postprocedural LBBB. Not unexpectedly, SURD-AVR patients with preexistent RBBB were more vulnerable for advanced AV block given that the conduction system was already impaired; in this group, RBBB emerged as dominant predictor for PPM implantation.

There is controversy about the effect of preoperative and postoperative antiarrhythmic drug use that may cause conduction disturbances after AVR. Yet, as reported by others (28), multivariable regression modelling failed to identify any role of antiarrhythmic drugs on the occurrence of postoperative conduction abnormalities in our cohort.

\section{Limitations}

The present study has certain limitations. It is a nonrandomized, retrospective analysis of prospectively collected data with a relatively small cohort of patients from a single center, and therefore conclusions are necessarily limited in their application. In addition, treatment biases for type of AVR technique were evident in our series as SURD-AVR interventions, compared with c-AVR, were more frequently performed in older female patients without BAV, aortic regurgitation, reduced left ventricular function and renal failure. Of note, after controlling for the estimated probability of AVR technique and acknowledged determinants of PPM implantation, the latter was not influenced by the AVR technique.

\section{Conclusions}

Our study revealed that the risk of PPM implantation in patients receiving surgical AVR is heavily influenced by the presence of pre-existing conduction disturbances, namely first-degree AV block and RBBB, rather than the type of valve prosthesis. Indeed, SURD-AVR and c-AVR demonstrated similarly low incidences of PPM implantation in patients with normal preoperative conduction; conversely, SURD-AVR emerged as independent predictor for new onset LBBB and was associated with a markedly increased risk of PPM in patients presenting with RBBB. We believe that the knowledge of the respective postAVR PPM risks for different valve technologies will result in patient-tailored valve selection with improved clinical outcomes.

\section{Acknowledgments}

None.

\section{Footnote}

Conflicts of Interest: The authors have no conflicts of interest to declare.

Ethical Statement: Patient-informed consent for treatment, data collection and analysis for scientific purposes was collected in all cases and the local Institutional Review Board approved the use of data for research.

Open Access Statement: This is an Open Access article 
distributed in accordance with the Creative Commons Attribution-NonCommercial-NoDerivs 4.0 International License (CC BY-NC-ND 4.0), which permits the noncommercial replication and distribution of the article with the strict proviso that no changes or edits are made and the original work is properly cited (including links to both the formal publication through the relevant DOI and the license). See: https://creativecommons.org/licenses/by-nc-nd/4.0/.

\section{References}

1. Berretta P, Di Eusanio M. Aortic valve replacement with sutureless and rapid deployment aortic valve prostheses. J Geriatr Cardiol 2016;13:504-10.

2. Berretta P, Andreas M, Carrel TP, et al. Minimally invasive aortic valve replacement with sutureless and rapid deployment valves: a report from an international registry (Sutureless and Rapid Deployment International Registry). Eur J Cardiothorac Surg 2019;56:793-9.

3. Phan K, Tsai YC, Niranjan N, et al. Sutureless aortic valve replacement: a systematic review and meta-analysis. Ann Cardiothorac Surg 2015;4:100-11.

4. Santarpino G, Berretta P, Fischlein T, et al. Operative outcome of patients at low, intermediate, high and 'very high' surgical risk undergoing isolated aortic valve replacement with sutureless and rapid deployment prostheses: results of the SURD-IR registry. Eur J Cardiothorac Surg 2019;56:38-43.

5. Borger MA, Dohmen PM, Knosalla C, et al. Haemodynamic benefits of rapid deployment aortic valve replacement via a minimally invasive approach: 1-year results of a prospective multicentre randomized controlled trial. Eur J Cardiothorac Surg 2016;50:713-20.

6. Meco M, Montisci A, Miceli A, et al. Sutureless Perceval Aortic Valve Versus Conventional Stented Bioprostheses: Meta-Analysis of Postoperative and Midterm Results in Isolated Aortic Valve Replacement. J Am Heart Assoc 2018;7. doi: 10.1161/JAHA.117.006091.

7. Lazkani M, Yerasi C, Prakash S, et al. Permanent pacemaker implantation and paravalvular leak rates following sutureless aortic valve operations. J Card Surg 2018;33:808-17.

8. Ensminger S, Fujita B, Bauer T, et al. Rapid Deployment Versus Conventional Bioprosthetic Valve Replacement for Aortic Stenosis. J Am Coll Cardiol 2018;71:1417-28.

9. Andreas M, Wallner S, Habertheuer A, et al. Conventional versus rapid-deployment aortic valve replacement: a singlecentre comparison between the Edwards Magna valve and its rapid-deployment successor. Interact Cardiovasc Thorac Surg 2016;22:799-805.

10. Di Eusanio M, Phan K, Berretta P, et al. Sutureless and Rapid-Deployment Aortic Valve Replacement International Registry (SURD-IR): early results from 3343 patients. Eur J Cardiothorac Surg 2018;54:768-73.

11. Fujita B, Schmidt T, Bleiziffer S, et al. Impact of new pacemaker implantation following surgical and transcatheter aortic valve replacement on 1-year outcome. Eur J Cardiothorac Surg 2020;57:151-9.

12. Surawicz B, Childers R, Deal BJ, et al. AHA/ACCF/ HRS recommendations for the standardization and interpretation of the electrocardiogram: part III: intraventricular conduction disturbances: a scientific statement from the American Heart Association Electrocardiography and Arrhythmias Committee, Council on Clinical Cardiology; the American College of Cardiology Foundation; and the Heart Rhythm Society. Endorsed by the International Society for Computerized Electrocardiology. J Am Coll Cardiol 2009;53:976-81.

13. 2013 ESC Guidelines on cardiac pacing and cardiac resynchronization therapy. Eur Heart J 2013;34:2281-329.

14. Di Eusanio M, Vessella W, Carozza R, et al. Ultra fasttrack minimally invasive aortic valve replacement: going beyond reduced incisions. Eur J Cardiothorac Surg 2018;53:ii14-8.

15. Berretta P, Cefarelli M, Montecchiani L, et al. Minimally invasive versus standard extracorporeal circulation system in minimally invasive aortic valve surgery: a propensity score-matched study. Eur J Cardiothorac Surg 2020;57:717-23.

16. Berretta P, Cefarelli $M$, Vessella $W$, et al. Ultra fast track surgery: a rapid deployment aortic valve replacement through a J-ministernotomy. J Vis Surg 2018;4:90.

17. Nguyen V, Michel M, Eltchaninoff H, et al. Implementation of Transcatheter Aortic Valve Replacement in France. J Am Coll Cardiol 2018;71:1614-27.

18. Walther T, Hamm CW, Schuler G, et al. Perioperative Results and Complications in 15,964 Transcatheter Aortic Valve Replacements: Prospective Data From the GARY Registry. J Am Coll Cardiol 2015;65:2173-80.

19. Grover FL, Vemulapalli S, Carroll JD, et al. 2016 Annual Report of The Society of Thoracic Surgeons/American College of Cardiology Transcatheter Valve Therapy Registry. J Am Coll Cardiol 2017;69:1215-30.

20. Fujita B, Ensminger S, Bauer T, et al. Trends in practice and outcomes from 2011 to 2015 for surgical aortic valve 
replacement: an update from the German Aortic Valve Registry on 42776 patients. Eur J Cardiothorac Surg 2018;53:552-9.

21. Friedman HS, Zaman Q, Haft JI, et al. Assessment of atrioventricular conduction in aortic valve disease. $\mathrm{Br}$ Heart J 1978;40:911-7.

22. Fukuda T, Hawley RL, Edwards JE. Lesions of conduction tissue complicating aortic valvular replacement. Chest 1976;69:605-14.

23. Nguyen A, Stevens LM, Bouchard D, et al. Early Outcomes with Rapid-deployment vs Stented Biological Valves: A Propensity-match Analysis. Semin Thorac Cardiovasc Surg 2018;30:16-23.

24. Forcillo J, Bouchard D, Nguyen A, et al. Perioperative outcomes with sutureless versus stented biological aortic valves in elderly persons. J Thorac Cardiovasc Surg

Cite this article as: Berretta $\mathrm{P}$, Montecchiani L, Vagnarelli F, Cefarelli M, Alfonsi J, Zingaro C, Capestro F, Pierri MD, D'alfonso A, Di Eusanio M. Conduction disorders after aortic valve replacement: what is the real impact of sutureless and rapid deployment valves? Ann Cardiothorac Surg 2020;9(5):386395. doi: 10.21037/acs-2020-surd-26
2016;151:1629-36.

25. Mogilansky C, Balan R, Deutsch C, et al. New postoperative conduction abnormalities after the implantation of a rapid-deployment aortic valve prosthesis. Interact Cardiovasc Thorac Surg 2019;28:581-6.

26. Vogt F, Moscarelli M, Nicoletti A, et al. Sutureless Aortic Valve and Pacemaker Rate: From Surgical Tricks to Clinical Outcomes. Ann Thorac Surg 2019;108:99-105.

27. El-Khally Z, Thibault B, Staniloae C, et al. Prognostic significance of newly acquired bundle branch block after aortic valve replacement. Am J Cardiol 2004;94:1008-11.

28. Erdogan HB, Kayalar N, Ardal H, et al. Risk factors for requirement of permanent pacemaker implantation after aortic valve replacement. J Card Surg 2006;21:211-5; discussion 216. 


\begin{tabular}{|c|c|c|}
\hline Variable & $P$ value for $P M$ & $P$ value for $\angle B B B$ \\
\hline \multicolumn{3}{|l|}{ Patients characteristics } \\
\hline Male & 0.3 & 0.5 \\
\hline Age (years) & 0.02 & 0.5 \\
\hline NYHA class & 0.6 & 0.8 \\
\hline Hypertension & 0.9 & 0.5 \\
\hline Obesity & 0.7 & 0.04 \\
\hline Diabetes & 0.2 & 0.9 \\
\hline \multicolumn{3}{|l|}{ Aortic valve disease } \\
\hline Aortic valve stenosis & 0.3 & 0.6 \\
\hline Aortic valve regurgitation & 0.6 & 0.7 \\
\hline Mixed aortic valve disease & 0.9 & 0.9 \\
\hline Bicuspid aortic valve & 0.9 & 0.03 \\
\hline CAD & 0.5 & 0.7 \\
\hline Prior AMI & 0.9 & 0.9 \\
\hline Pulmonary hypertension & 0.9 & 0.2 \\
\hline Cerebrovascular disease & 0.06 & 0.7 \\
\hline Peripheral vasculopathy & 0.1 & 0.2 \\
\hline Renal insufficiency (GFR $<50 \mathrm{~mL} / \mathrm{min}$ ) & 0.3 & 0.5 \\
\hline Dialysis & 0.06 & 0.9 \\
\hline Chronic lung disease & 0.2 & 0.9 \\
\hline Reduced LVEF (<50\%) & 0.3 & 0.9 \\
\hline Euroscore II (\%) & 0.6 & 0.8 \\
\hline \multicolumn{3}{|l|}{ Baseline ECG data } \\
\hline Sinus rhythm & 0.4 & 0.6 \\
\hline Atrial fibrillation & 0.7 & 0.6 \\
\hline First degree AV block & 0.02 & \\
\hline RBBB & 0.003 & 0.01 \\
\hline LBBB & 0.9 & 0.9 \\
\hline LAFB & 0.5 & 0.6 \\
\hline \multicolumn{3}{|l|}{ Preoperative antiarrhythmic drugs } \\
\hline Beta blocker & 0.4 & 0.1 \\
\hline Calcium channel blockers & 0.9 & 0.9 \\
\hline Amiodarone & 0.9 & 0.2 \\
\hline Digoxin & 0.9 & 0.9 \\
\hline \multicolumn{3}{|l|}{ Operative data } \\
\hline Ministernotomy & 0.08 & 0.4 \\
\hline ART & 0.08 & 0.4 \\
\hline SURD-AVR & 0.009 & $<0.001$ \\
\hline MiECC & 0.9 & 0.09 \\
\hline UFT anesthesia & 0.9 & 0.2 \\
\hline CPB time (min) & 0.6 & 0.08 \\
\hline Cross-clamp time (min) & 0.5 & 0.08 \\
\hline \multicolumn{3}{|l|}{ Postoperative antiarrhythmic drugs } \\
\hline Beta blocker & 0.03 & 0.6 \\
\hline Calcium channel blockers & 0.9 & 0.9 \\
\hline Amiodarone & 0.06 & 0.3 \\
\hline Digoxin & 0.9 & 0.9 \\
\hline
\end{tabular}

AMI, acute myocardial infarction; ART, anterior right thoracotomy; AV, atrioventricular; CAD, coronary artery disease; CPB, cardio-pulmonary bypass; ECG, electrocardiogram; GFR, glomerular filtration rate; LAFB, left anterior fascicular block; LBBB, left bundle branch block; LVEF, left ventricular ejection fraction; MiECC, minimally invasive extracorporeal circulation; RBBB, right bundle branch block; SD, standard deviation; SURD-AVR, sutureless and rapid deployment aortic valve replacement; UFT, ultra fast track. 